\title{
A New Three-Input and One-Output Current-Mode Universal Filter Using Unity-Gain Cells
}

\author{
Chih-Lung Lin, Ro-Min Weng, Sheng-Yu Peng, Maw-Huei Lee, and Te-Son Kuo \\ Department of Electrical Engineering, National Taiwan University \\ Taipei, Taiwan, R.O.C \\ Tel No:886-02-23635251 Ext.537, Fax No: 886-02-23638247 \\ Email : cllin@ee.cc.ntu.edu.tw
}

\begin{abstract}
:
A new current-mode universal filter using unitygain current and voltage followers is presented. The filter has three inputs and one output. It offers the following advantageous features: realisation of highpass, bandpass, lowpass, notch, and allpass filter without any changes in the circuit topology, low active and passive sensitivities, no requirement for critical matching, and fewer active and passive elements. Moreover, the current mode circuit is suitable for integrated circuit implementation for using grounded capacitors. PSPICE simulated results that confirm the theoretical analysis are obtained.
\end{abstract}

\section{Introduction}

The current-mode monolithic active components using new integration process are able to operate accurately in an open loop and improve the dynamic behaviour of the classical operational amplifier. Circuits based on the current-mode components are becoming popular due to their high frequency operation and wide dynamic range. There are many design applications of universal biquad filters employing several current mode active elements (Fabre et al.1995, Tsukutani et al.1996, Liu 1995). Current Conveyor (CC) is one of the active components found useful in universal biquad filters design. However, circuits using CC's will be limited mainly due to the voltage and current transfer ratios. From the point of view of active sensitivity, using unitygain cells such as followers could avoid some of the tracking errors in CC's. Recently, there has been a growing interest in designing current-mode and voltagemode continuous-time filters using unity-gain current mirrors and/or voltage followers (Zele et al. 1993, Tsivids et al. 1994, Celma, et al. 1995, Muhammad et al. 1996, Weng et al. 1997 ). This is attributed to their low power dissipation and high frequency operation. These filters (Zele et al. 1993, Tsivids et al. 1994, Celma, et al. 1995), however, cannot be realised without changing the circuit topology to achieve a specific function. In 1996, Muhammad presented a universal filter structure which can implement all the basic second-order filter functions (lowpass, highpass, bandpass, notch and allpass) without adding any additional active elements and changing the circuit topology. We propose a new universal filter circuit which need fewer active and passive elements than Muhammad's circuit to implement all the basic second-order filter functions. The multiple output unity gain current follower can be easily obtained from the multiple output second-generation current conveyor (CCII) by grounding its high input impedance terminal (Muhammad et al. 1996, Wu et al. 1996).

\section{Circuit description:}

A current follower (CF) is a two-port network whose terminal characteristics can be described as $V_{x}=0$, and $i_{z}= \pm i_{x}$ where the plus and minus signs denote $\mathrm{CF}+$ and $\mathrm{CF}$-, respectively. A voltage follower (VF) is also a two-port network whose terminal characteristics can be described by $i_{y}=0$, and $V_{x}=V_{y}$. Their network symbols are shown in Fig. 1(a) and (b).

The circuit is shown in Fig. 2. Using standard notations, the multiple output current followers $\mathrm{CF} \pm$ can be characterized by $i_{z k}= \pm \alpha_{n k} i_{x}, n=1-3$, where $\alpha_{n k}=1-\varepsilon_{n k},\left|\varepsilon_{n k}\right| \ll 1$ represents the current tracking error of the $k$ th output for the $n$th current follower. The unity-gain voltage follower can be characterized by $v_{x}=\beta_{n} v_{y}, \quad n=1-2$, where $\quad \beta_{n}=1-\delta_{n},\left|\delta_{n}\right| \ll 1$ represents the voltage tracking error of the $n$th voltage follower. Routine analysis yields the current transfer function:

$$
I_{O}=\alpha_{32} \frac{I_{1}\left(s^{2}\right)-I_{2}\left(\frac{\alpha_{2} \beta_{2}}{R_{2} C_{2}} s\right)+I_{3}\left(\frac{\alpha_{1} \alpha_{2} \beta_{1} \beta_{2}}{R_{1} R_{2} C_{1} C_{2}}\right)}{s^{2}+\frac{\alpha_{2} \alpha_{33} \beta_{2}}{R_{2} C_{2}} s+\frac{\alpha_{1} \alpha_{2} \alpha_{31} \beta_{1} \beta_{2}}{R_{1} R_{2} C_{1} C_{2}}}
$$

The angular frequency $\omega_{0}$ and quality factor $Q_{0}$ are given by

$$
\begin{aligned}
& \omega_{0}=\left(\frac{\alpha_{1} \alpha_{2} \alpha_{31} \beta_{1} \beta_{2}}{R_{1} R_{2} C_{1} C_{2}}\right)^{1 / 2} \\
& Q_{0}=\frac{1}{\alpha_{33}}\left(\frac{R_{2} C_{2} \alpha_{1} \alpha_{31} \beta_{1}}{R_{1} C_{1} \alpha_{2} \beta_{2}}\right)^{1 / 2}
\end{aligned}
$$


Five types of biquadratic filters are realised with the following specialisation :

(i) highpass : $I_{2}=I_{3}=0$, input signal is $I_{1}$;

(ii) lowpass : $I_{1}=I_{2}=0$, input signal is $I_{3}$;

(iii) bandpass: $I_{1}=I_{3}=0$, input signal is $I_{2}$;

(iv) notch: $I_{2}=0$ and $I_{1}=I_{3}=$ input signal ;

(v) allpass: $I_{1}=I_{2}=I_{3}=$ input signal ;

Thus, the quality factor $Q_{0}$ can be controlled by the ratio of $\mathrm{R}_{2} / \mathrm{R}_{1}$ or $\mathrm{C}_{2} / \mathrm{C}_{1}$.

From Eqns. 2 and 3 it is easy to show that the active and passive sensitivities of the parameters $\omega_{0}$ and $\mathrm{Q}_{0}$ are

$$
\begin{aligned}
& S_{R_{1}, R_{2}, C_{1}, C_{2}}^{\omega_{0}}=-S_{\alpha_{1}}^{\omega_{0}}=-S_{\alpha_{2}}^{\omega_{0}}=-S_{\alpha_{31}}^{\omega_{0}}=-S_{\beta_{1}}^{\omega_{0}}=-S_{\beta_{2}}^{\omega_{0}}=-\frac{1}{2} \\
& S_{R_{1}, C_{1}}^{Q_{0}}=-S_{R_{2}, C_{2}}^{Q_{0}}=-S_{\alpha_{1}}^{Q_{0}}=S_{\alpha_{2}}^{Q_{0}}=-S_{\alpha_{31}}^{Q_{0}}=-S_{\beta_{1}}^{Q_{0}}=S_{\beta_{2}}^{Q_{0}}=-\frac{1}{2}, \\
& S_{\alpha_{33}}^{Q_{0}}=-1 .
\end{aligned}
$$

all of the passive and active sensitivities are small and no greater than unity.

\section{Biquad Realisation}

Finally, to verify theoretical prediction of the proposed circuit, shown in Fig. 2, consider the biquad characteristics with the chosen values for passive components: $\mathrm{C}_{1}=\mathrm{C}_{2}=318 \mathrm{pF}$, and $\mathrm{R}_{1}=\mathrm{R}_{2}=5 \mathrm{k} \Omega$. This choice leads to $\mathrm{f}_{0}=\omega_{0} / 2 \pi=100 \mathrm{kHz}$, and $\mathrm{Q}_{0}=1$. In PSPICE simulation, second generation current conveyors CCIIs (implemented by AD844 ICs from Analog Devices) have been used to realise $\mathrm{CF}$ and VF. The current-mode frequency responses of the highpass, bandpass, and lowpass filter are showing in Fig. 3. The notching filtering gain and phase responses are shown in Fig. 4. The allpass filtering gain and phase responses are shown in Fig. 5. The simulation results confirm the theoretical analysis.

\section{Conclusions:}

In summary, the proposed new current-mode universal biquad filter with three inputs and one output using only two VFs, three CFs ( including one threeoutput CF ), two resistors, and two grounded capacitors is presented. The circuit provides the following advantages:

(i) realisation of highpass, bandpass, lowpass, notch, allpass filtering from the same configuration.

(ii) using unity-gain cells could avoid some of the tracking errors in CC's.

(iii) low passive and active sensitivites. (iv) fewer passive and active components.

\section{References}

[1] S. CELMA, J. SABADELL, and P. MARTINE, "Universal filter using unity-gain cells", Electron. Lett., 31, pp. 1817-1818, 1995.

[2] A. FABRE, and M. ALAMI, "Universal current mode biquad implementated from two second generation current conveyors", IEEE Trans. CAS., 42.(7), pp.383-385, 1995.

[3] S. -I. LIU, "Universal filter using two currentfeedback amplifiers", Electron. Lett., 31.(8), pp.629-630, 1995.

[4] S. -I. LIU, J. -J CHEN, and Y. -S. HWANG, "New current mode biquad filters using current followers", IEEE Trans. CAS., 42.(7),pp.380-383, 1995.

[5] T. A. MUHAMMAD, and A. A. MUHAMMAD, "Current-mode universal filters using-unity gain cells", Electron. Lett., 32, pp. 1077-1078, 1996.

[6] S. SELMA, J. SABADELL, and P. MARTINEZ, "Universal filter using unity-gain cells", Electron. Lett., 31(21), pp.1817-1818, 1995.

[7] Y. TSIVIDIS, and Y. PAPANANOS, "Continuous time filters using buffers with gain lower than unity", Electron. Lett., 30, pp. 629-630, 1994.

[8] T. TSUKUTANI, M. ISHIDA and Y. FUKUI, "Current-mode biquad without external passive elements", Electron Lett., 32.(3), pp. 197-198, 1996.

[9] R. -M. WENG, M. -H. LEE, "Novel universal biquad filters using only three followers", Int. $J$. Electronics, 82. (6), pp. 621-628, 1997.

[10] J. WU, and E. EI-Masry, "Current-mode ladder filters using multiple output current conveyors", IEE Proc.Circuit Devices Syst., 143, pp.218-222, 1996.

[11] R. H. ZELE, D. J. ALLSTOT, and T. S. FIEZ, "Fully balanced CMOS current-mode circuits", IEEE J. Solid-State Circuits, 28, pp. 569-575, 1993 


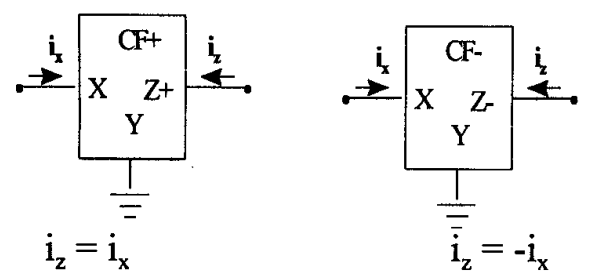

Fig.1(a) Symbol of current follower

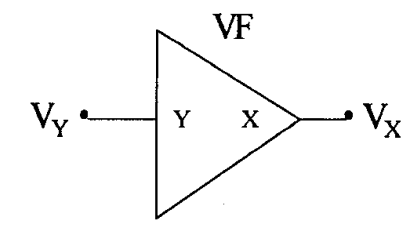

Fig.1(b) Symbol of voltage follower

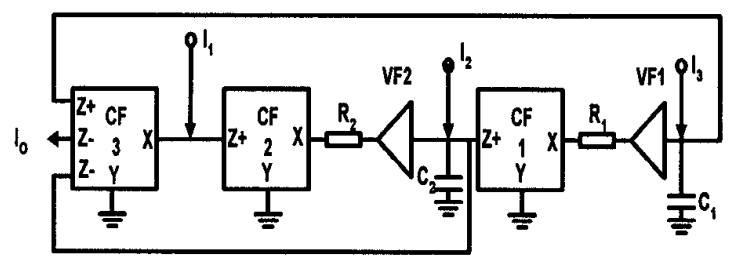

Fig. 2 Proposed universal biquad filter



Fig. 3 Simulated results of lowpass, bandpass, and highpass responses

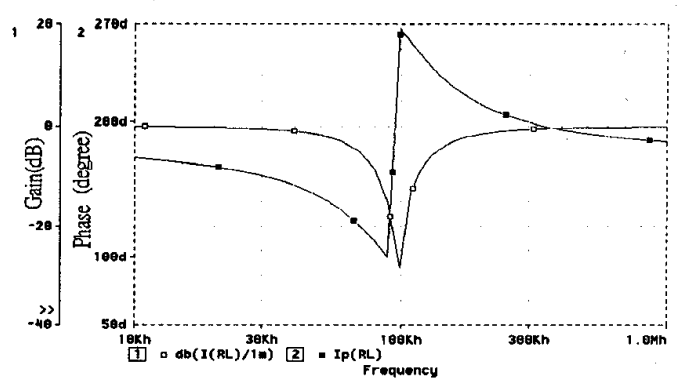

Fig. 4 Simulated results of notch responses

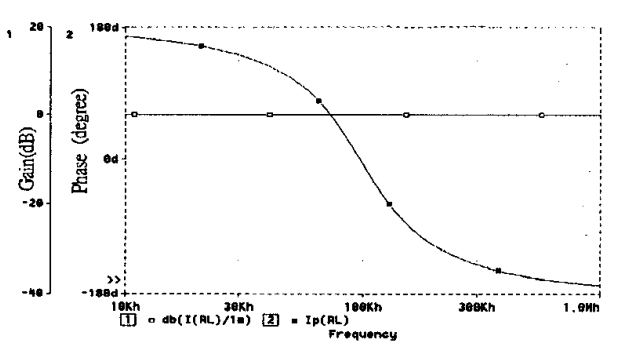

Fig. 5. Simulated results of allpass responses 